full-fed larvæ are easily found in quantity early in the summer term. A test could also be made of the presence of an instinct in the larva to make its cocoon on a tall waving grass stem rather than on more solid objects, and also whether the larva will be satisfied with any height of stem, or will come down again from one that is too short for safety and seek for a longer one. It is obvious that such an instinct would be selected by attacks such as have been described.

Hope Department of Entomology,

$$
\text { G. D. Hale Carpenter. }
$$

University Museum, Oxford.

\section{Stability after the War}

THE programme of the United Nations, as broadcast at the end of 1943 , may at its briefest be stated thus : the Germans and Japanese are to be defeated and disarmed, and thereafter watched for so long a time as may be necessary by an armed force controlled by the United Nations, who are firmly resolved to remain united.

Historical facts, taken alone, do not predict the future; they do so only if they are combined with some hypothesis. A general form of hypothesis for the quantitative interaction of two entities is a pair of simultaneous differential equations, having time $t$ as independent variable. Almost the simplest of such piirs is

$$
d x / d t=g-\alpha x+k y, \quad d y / d t=h+l x-\beta y,
$$

where $g, h, \alpha, \beta, k, l$, are constants. The most relevant of the quantitative historical facts are the numbers of persons engaged on war-preparations in the opposing groups. Let these be $x$ and $y$. It is then found that the equations (1) are capable of describing the European $x$ and $y$ for the years 1908-13 and again for 1933-38, during the greater part of the arms-races ${ }^{1}$. Moreover, the constants have psychologically intelligible names, thus: $g, h$, grievances and ambitions; $k, l$, defence coefficients; $\alpha, \beta$, fatigue-and-expense coefficients. This analysis emphasizes, what is also obvious to common sense, namely, that if the several nations, now united, were to attempt to regain their former so-called freedom, sovereignty and independence, then after the present War had faded out of mind, disastrous arms-races would be likely to develop between them.

The other essential part of their programme is the submission of the defeated. Equations (1) are too simple to describe defeat or submission. For this purpose it is necessary to introduce at least the quadratic term in the constant $\rho$, which has been called a 'submissiveness', thus ${ }^{2}$

$$
\left.\begin{array}{l}
d x / d t=g-\alpha x+k y, \\
d y / d t=h+l x\{1-p(x-y)\}-\beta y .
\end{array}\right\}
$$

It is very ominous that the turn in the year 1930 from the long pause into the arms-race can be described by equations (2). I am not saying that no other motives were operative. On the contrary, it seems almost certain that the great trade depression and the fading of war-weariness were involved. But I do say that there is no warrant either in those facts or in that theory for the belief that Europe will be permanently stabilized by submissiveness in the presence of grievances, ambitions, defensiveness, and the dislike of fatigue and expense. Balance of power, according to the theory, may be of various types, some stable, some unstable. The need for some other and more binding motive is clearly indicated.

Hillside House, Kilmun,

Lewis F. Richardson.

Argyll. July 1.

${ }^{1}$ Nature, 135,$830 ; 136,1025 ; 142,792$; and much yet unpublished. 2 "Generalized Foreign Polities", 23 (Camb. Univ. Press, 1939).

\section{A Halo Phenomenon}

AT 10.15 a.m. G.M.T. on May 2 last some cirrus clouds drifted across the sun; I suspect that they were the remains of condensation trails. As they passed over, I noticed a very peculiar halo phenomenon. The part first visible was the arc $M^{\prime} X^{\prime}$; I did not suspect that it was part of a halo circle, though it struck me that it was very like one; I took it to be a long wisp of cirrus or part of a condensation trail. But there then appeared at $M^{\prime}$ a very brightly coloured parhelion, and at the same time I noticed part of a $22^{\circ}$ halo at $A, B$. A few minutes later the are $X^{\prime} M^{\prime}$ had extended through the sun $(S)$ to $M$ and $X$; there was another brightly coloured parhelion at $M$; I think that $M$ and $M^{\prime}$ were rather more than $22^{\circ}$ from the sun. The whole phenomenon lasted a very few minutes; I went indoors to get a camera, but by the time I came out again it was all over.

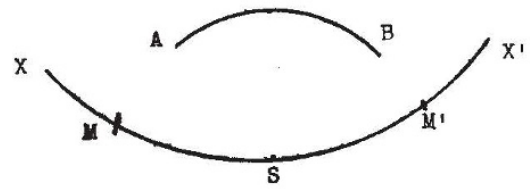

I am quite sure that the arc of the circle through the sun was part of a vertical circle and not part of the horizontal parhelic circle, though like the latter it was white. I am not sufficiently up in meteorological optics to know whether a white vertical circle passing through the sun at its lowest point has been previously observed, but in any event it must be extremely rare. The figure is purely diagamatic; there was no time to take any measurements.

Stoner Hill, Petersfield. C. J. P. Cave.

\section{Centenary of Dalton's Death}

THE Manchester Literary and Philosophical Society, which was so closely associated with John Dalton during the whole of his life in Manchester, is commemorating his work on the occasion of the centenary of his death which falls this year. The first meeting of next session is to be devoted to a memorial lecture. In connexion with it the Society hopes to publish a memorial volume in which it would be of interest to give the whereabouts of relics of Dalton, many of those which the Society possessed having been destroyed as a result of fires started by enemy action. The secretaries would therefore welcome any information relating to Dalton's scientific interests or his connexion with the Society. They are also in a position to receive gifts or offers of gifts.
C. M. LEGGE.
D. E. WhEELER. (Hon. Secretaries.)

12 Brooklands Avenue,

Manchester, 20. 